Journal of Sociology, Psychology \& Religious Studies

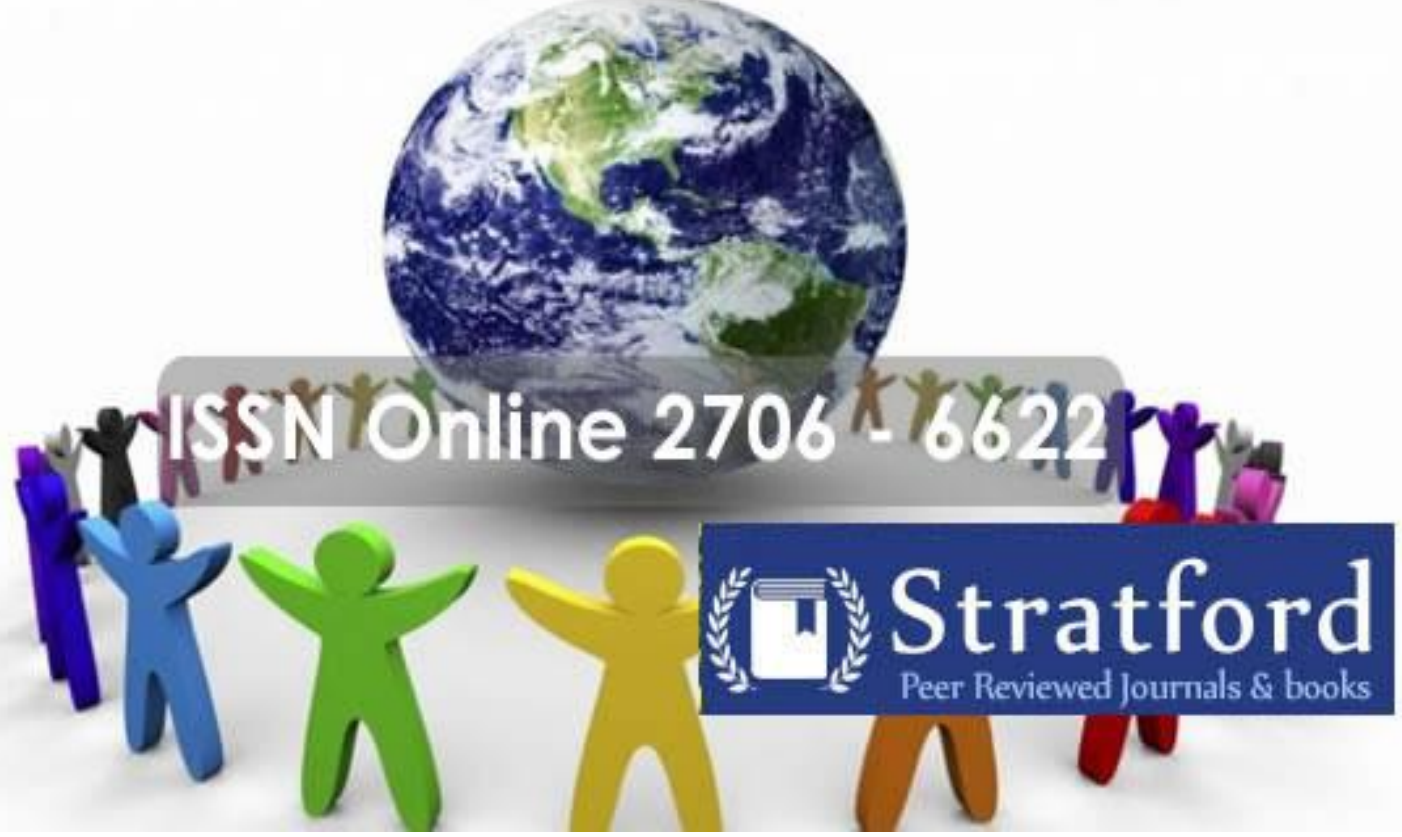

Juvenile Delinquency in the United States of America

Haveripet, Young and Cavan Giller

ISSN: 2706-6622 


\title{
Juvenile Delinquency in the United States of America
}

\author{
${ }^{1 *}$ Haveripet Young and ${ }^{2}$ Cavan Giller \\ 1,2 Bureau of Justice Statistics, NW Washington, D.C. \\ *Corresponding authors' email address: hyoung@bjs.org
}

\begin{abstract}
How to cite this article: Young, H. \& Giller, C. (2021). Juvenile Delinquency in the United States of America. Journal of Sociology, 3(4), 1-7. https://doi.org/10.53819/81018102t3009
\end{abstract}

\begin{abstract}
Juvenile delinquency remains a major emerging social problem globally. Statistics shows that crime among persons aged 18 years and below is on the rise. This paper relied much on literature review approach. Past studies were reviewed to uncover the actual situation regarding juvenile delinquency in the United States. The current juvenile justice system is broken and needs to be dismantled. Better programs should be put into place to ensure they have a chance at a positive outcome of their life. The first step in all of this is listening to children, not just hearing what they are saying. By listening to children, their needs could be better-assessed to think of how the youth globally would change. The positive roles of mainly parents, various community leaders, and interested groups whom adolescents look up to for guidance, were alluded to and emphasized as a desirable contribution to the normal socialization of adolescents. Desired policy formulations indicated above should be a product of experts from various government departments such as health, social welfare, justice, and correctional services. The voice of teachers, parents and youth should complete the list of stakeholders.
\end{abstract}

Key words: Juvenile Delinquency, United States of America 


\subsection{Introduction}

Juvenile delinquency also known as juvenile offending refers to illegal acts whether criminal or status offences, which are committed by young people under the age of 18 years (Shoemaker, 2010). Delinquency is a problem to the family, public safety, the lives of young people themselves and law enforcement agencies at large and as a result a country has to bear a lot of costs associated with delinquency cases (Cicourel, 2017). It is a major challenge most children go through regularly and this to a large extent affects their physical, psychological and societal needs at large (Hirschi \& Selvin, 2017)). According to Nasir, Zamani and Khairudin (2010) there are four types of delinquencies; individual delinquency, groupsupported delinquency, organized delinquency and situational delinquency. Individual delinquency refers to delinquency in which only one individual is involved in committing a delinquent act, group-supported delinquency is a form of delinquency where criminal activities are carried out by a group of children (Elliott, 2015). According to Young, Greer and Church (2017) organized delinquency refers to delinquency committed by developing formally organized groups while situational delinquency is a form of delinquency in which only one individual is involved in committing a delinquent act and its cause is located within the individual delinquent.

Hirsch (2017) classified juvenile delinquents in six groups on the basis of kinds of offences committed: Incorrigibility (for example, disobedience and keeping late hours), Truancy (staying away from school), Larceny (ranging from petty thefts to armed robbery), destruction of property (both public and private), violence against individual or community and sexual offences ranging from homosexuality to rape. Sharma, Dhillon and Bano (2009), classified delinquents into five groups according to the offence: minor violations (disorderly conduct and minor traffic violations), major violations including thefts, property violations, Addiction, and bodily harm including homicide and rape. Hirschi (2017) classified them as accidental, ill-socialized, aggressive, occasional, professional and gang-organized. Psychologists Feld (2019) and Walker and Maddan (2019) have classified juvenile delinquents on the basis of their individual traits or the psychological dynamics of their personality into five groups: mentally defective, psychotic, neurotic, situational and cultural.

Sociological theories of juvenile delinquency put emphasis on the environment, social structures and the learning process (Baglivio, Wolff, Piquero \& Epps, 2015). However, it is generally agreed that a number of factors that play an important part in a youngster's delinquent behavior can be divided into two groups, individual factors and situational factors (Ansell, 2016). The individual factors include personality traits like submissiveness, defiance, hostility, impulsiveness, feeling of insecurity, fear, lack of self-control and emotional conflicts while situational factors may be attributed to family, companions, movies, school environment and work environment (Haveripet, 2013).

Globally, the problem of juvenile delinquency has grown significantly from 2009-2019 (Feld, 2019). United Nations Office on Drugs and Crime (2019) global survey of juvenile crime in cities, conducted by UNIHABITAT, collected considerable data on the dynamics of the problem. The United Nations Office on Drugs and Crime (2019) reported that in Europe, juvenile crime had increased by $2.6 \%$ compared to the previous year's increase of $1.7 \%$. South East Asia, Latin America and North America were reported to have juvenile crime 
growth rates of $0.7 \%, 3.9 \%$ and $1.8 \%$ respectively. The relatively high rate of juvenile crime in Latin America has been attributed to the drug economy in places like Mexico and Colombia (Raul, 2010). In Africa, according to UNIHABITAT, juvenile criminality has continued to increase largely as a result of chronic unemployment among youth. Between 2007 and 2019, juvenile crime increased from 3.2\% to 5.7\% (Walker \& Maddan, 2019).

In the United States crimes committed by delinquents aged 13-18 year olds have been rising significantly for offenses associated with street gangs, including homicide, robbery, theft, burglary and vandalism offenses (Arora, 2017). In 2017, law enforcement agencies in the U.S. made an estimated 809,700 arrests of persons under age 18 years. Juvenile arrests for murder increased to $18 \%$ in 2016 up from 15\% in 2015 (Juvenile Justice Statistics National Report, 2016). Owing to the delinquents' crime in the United States, communities across America in conjunction with government agencies and security agencies and community organizations have been taking action to reduce school crime.

According to Juvenile Justice Statistics National Report (2018) creating safe schools will require a comprehensive approach, where parents, teachers and government agencies work in collaboration in mitigated juvenile crime, supporting victims and offering counseling sessions for both victims and aggressors. While comprehensive safe school planning will not eliminate all school violence, if properly conceived and implemented, it will foster a safer environment for students and their teachers (Hockenberry, 2020). With the approach to abate juvenile crime no schools, there no standard set of indicators existing to describe school violence, and the indicators that are available have limitations. For example, data from the National Crime Victimization Survey, conducted by the Juvenile Justice Statistics National Report (2016), describe the extent to which students have been victims of crime at school. However, the data do not yield school level information that would provide a better understanding of which types of schools are experiencing the highest levels of crime.

\subsection{Statement of the Problem}

In the United States juvenile crime is a major problem. Since the late 1980s, there has been growing concern about crimes committed by young people. According Arora (2017) crimes committed by delinquents aged 13-18 year olds have been rising significantly for offenses associated with street gangs, including homicide, robbery, theft, burglary and vandalism offenses (Jannetta \& Okeke, 2017). In 2014, juvenile courts in the United States handled nearly 975,000 delinquency cases that involved juveniles charged with criminal law violations. However, Juvenile Justice Statistics National Report (2014) reported that from 2005 through 2014, the number of delinquency cases declined $42 \%$ across all four offense categories: property offense cases (down 46\%), public order offense cases (down 44\%), person offense cases (down 40\%), and drug law violation cases (down 30\%). In 2016, law enforcement agencies in the United States made more than 986,000 arrests of persons younger than 18 of age (Juvenile Justice Statistics National Report, 2016). Among violent crimes committed by the juvenile included aggravated assault and robbery (Young, Greer \& Church, 2017). Juvenile arrests for murder increased to 18\% in 2016 up from 15\% in 2015. There were an estimated 134,180 juvenile arrests for larceny-theft in 2016 (Juvenile Justice Statistics National Report, 2016). 


\subsection{Literature Review}

\subsection{Theoretical Framework}

The Theory of Differential Association, developed and authored by Edwin Sutherland, is a prominent criminological theory, rooted in sociology. Following Clifford Shaw and Henry McKay, Sutherland's observations encouraged him to build on their theory of social disorganization and expand the concept that individuals learn criminal behavior through the social organizations in which they are rooted or involved (Moon, Hwang \& McCluskey, 2011). While Sutherland concluded that there are two cultures in society, constantly competing with one another, his focus was on how an individual chooses which culture to be part of. In expressing his concept of "definitions," Sutherland established that there are definitions favorable to the violation of law" and "definitions unfavorable to the violation of law (Sutherland, Cressey \& Luckenbill, 1995).

Whichever definitions exceed those of the other set, will determine which culture that individual will be most influenced by. Sutherland established nine propositions explaining his observation that criminal behavior is, in fact, learned (Curran \& Renzetti, 2001). Through these propositions Sutherland established his theory of differential association to explain how criminals learn the techniques of particular criminal activities, and how to rationalize such behavior as normal and enjoyable. Sutherland proposed that an excess of definitions conducive to criminality could be learned by individuals and this theory has been as particularly useful in explaining juvenile gang crime and white collar crime (Lainer \& Henry, 2004). According to Sutherland two elements of differential association theory are that the learning process itself and the content of what is learnt are important in understanding and explaining youth delinquency and gang culture. Nine propositions posit that criminal behavior is learned. Criminal and deviants must witness criminal behaviour in order to learn it. It is learn through social interaction and communication. Sutherland argues that most learning of crime and deviance takes place in interaction with members of intimate, personal group and method of impersonal communication such as television, films or newspapers. Sutherland posited that criminal behaviour is as a result of social process of socialization (Scaggs, 2009). The theory is outlined in nine propositions. The first proposition posits that criminal behaviour is learned. Juvinie therefore learn deviant behaviours from threir peers. The second proposition according to Sutherland is that one learns criminal behaviour through social interaction and communication. When juvenile interact with one another they learn criminal behaviours from deviant children. The third proposition, Sutherland argues that most learning of crime and deviance take place interaction with members of intimate , personal groups, and that the methods of interpersonal communication such as television, films and newspapers are less influential or effective in learning. The greatest implication of this proposition is trust at the root of the social interactions that encourages deviance for example children and youth would likely first learn how to shop lift from their close friends rather than from general acquaintances.

The forth proposition identify what is acquired through communication with intimate others that enable criminal activity and how an individual gains not only the skills and techniques to commit the crime but also the motive, drives, rationalization and attitudes that accompany the behaviour. The fifth proposition elaborates the issue of criminal motivation as individuals are surrounded by a "culture conflict" of competing ideas from both law abiding citizens and criminals. Pro-criminal or anti criminal intentions are developed based on leaned conceptions 
of the law as either favorable or unfavorable (Katsiyannis et al., 2008). The sixth proposition according to Sutherland argues that an individual becomes delinquent only when definition favorable to violation of law exceeds definitions unfavorable to violation of law. Sutherland further states that it's not the amount of exposure to criminal ideology that is important but it's the ratio of attitudes (definition) towards crime whether pro-criminal or anti criminal influences are stronger which determines whether an individual embraces criminal behavior or note.

Seventh proposition in according to Sutherland describes how excess definitions (among locals forms attitudes, patterns etc) are affected by four factors of frequency, duration, priority and intensity for instance how long, how early in life, from whom an individual is exposed to criminal behavior which affect the relative impact on an individual behaviour. In the eighth proposition, Sutherland reiterates the logic behind the criminal learning process. Sutherland explains that like any other skills or knowledge the process by which one attains and develops pro-criminal and anti-criminal patterns on the same as any other learning process. For example a thief who still cars or burglars houses will sharpen his or her skills to become more efficient and effective over time to become quite faster and more precise in such activities. The nine proposition makes the important claim that the motivation from criminal and law abiding behaviour cannot be the same and therefore crime cannot be a result of general needs and values such as desires for wealth, social status. Example of a student who plagiarizes an assignment cannot be justified by a general define to do well academically thus would not explain why all students do not participate in the same deviant behaviours.

\subsection{Methodology}

This paper relied much on literature review approach. Past studies were reviewed to uncover the actual situation regarding juvenile delinquency.

\subsection{Empirical Literature}

Frías-Armenta, and Corral-Verdugo (2013) conducted a study on environmental and Individual Factors in Adolescent Anti-sociality: A Structural Model of Mexican Teenagers. The sample comprised 184 youths: half of whom were arrested by police, and the other half of whom were teenagers from the general population, matched by age and school grade to the arrested group. A structural equation model was used to estimate the relationships between a negative social environment, family violence, negative individual characteristics, and antisociality. Negative social environment had a positive effect on both family violence and individual characteristics; in turn, family violence affected negative individual characteristics, which then influenced antisociality. The results indicated that negative contextual variables facilitate the development of negative individual characteristics, which then puts adolescents at risk for getting involved in antisocial activities.

Elliott, (2015) explored the environmental factors contribute to juvenile crime and violence (From Juvenile Crime: Opposing Viewpoints. Research suggests that these forms of exposure to violence during childhood increase the risk of violent behavior during adolescence by as much as 40 percent. Environment, the school also has its own potential for generating conflict, frustration, and violent responses to these situations. There is evidence that school 
dropouts, drug dealers, and those with a prior record of violent behavior are more likely to own a gun than are other adolescents. Research findings suggest that growing up in poor, minority families and disorganized neighborhoods has two major effects directly related to violent behavior. Erude, Cara. (2020) studied juvenile deliquency in the United States versus Kenya. Children are our future, and without positive reinforcement from trusted adults, teachers, and parents or parental figures, it is no wonder that society has failed our children. Juvenile delinquency is an ongoing issue in the United States. Researchers have not been able to pinpoint one primary cause linked to delinquency.

\subsection{Conclusion}

Juvenile delinquency remains a major emerging social problem globally. Statistics shows that crime among persons aged 18 years and below is on the rise. Since the late 1980s, there has been growing concern about crimes committed by young people. Crimes committed by delinquents aged 13-18 year olds have been rising significantly for offenses associated with street gangs, including homicide, robbery, theft, burglary and vandalism offenses. In 2014, juvenile courts in the United States handled nearly 975,000 delinquency cases that involved juveniles charged with criminal law violations.

\subsection{Recommendations}

The current juvenile justice system is broken and needs to be dismantled. Better programs should be put into place to ensure they have a chance at a positive outcome of their life. The first step in all of this is listening to children, not just hearing what they are saying. By listening to children, their needs could be better-assessed to think of how the youth globally would change. The positive roles of mainly parents, various community leaders, and interested groups whom adolescents look up to for guidance, were alluded to and emphasized as a desirable contribution to the normal socialization of adolescents. Desired policy formulations indicated above should be a product of experts from various government departments such as health, social welfare, justice, and correctional services. The voice of teachers, parents and youth should complete the list of stakeholders. 


\section{REFERENCES}

Baglivio, M. T., Wolff, K. T., Piquero, A. R., \& Epps, N. (2015). The relationship between adverse childhood experiences (ACE) and juvenile offending trajectories in a juvenile offender sample. Journal of Criminal Justice, 43(3), 229-241.

Cicourel, A. V. (2017). The social organization of juvenile justice. Routledge.

Elliott, D. S. (2015). Environmental Factors Contribute to Juvenile Crime and Violence (From Juvenile Crime: Opposing Viewpoints, P 83-89, 2015, AE Sadler, ed.--See NCJ-167319).

Erude, Cara. (2020). Juvenile Deliquency in the United States versus Kenya A Cross-Cultural Comparison final document. Western Illinois University.

Feld, B. C. (2019). The evolution of the juvenile court: Race, politics, and the criminalizing of juvenile justice (Vol. 4). NYU Press.

Frías-Armenta, M., \& Corral-Verdugo, V. (2013). Environmental and Individual Factors in Adolescent Anti-sociality: A Structural Model of Mexican Teenagers. International Journal of Criminal Justice Sciences, 8(2), 198-214.

Hirschi, T. (2017). Causes of delinquency. New York, YK: Routledge.

Hirschi, T., \& Selvin, H. C. (2017). Delinquency research: An appraisal of analytic methods. Routledge.

Hockenberry, S. (2020). Juveniles in Residential Placement, 2017. Juvenile Justice Statistics: National Report Series Bulletin. NCJ 254498. Office of Juvenile Justice and Delinquency Prevention.

Jannetta, J., \& Okeke, C. (2017). Strategies for Reducing Criminal and Juvenile Justice Involvement. Building Ladders of Opportunity for Young People in the Great Lakes States, brief, 4.

Meher, R., Arora, N., Bhargava, E. K., \& Juneja, R. (2017). Massive juvenile nasopharyngeal angiofibroma: ode to the open surgical approach. Case Reports, 2017, bcr-2016.

Nasir, R., Zamani, Z. A., \& Khairudin, R. (2010). Effects of family functioning, self-esteem, and cognitive distortion on depression among Malay and Indonesian juvenile delinquents. Procedia-Social and Behavioral Sciences, 7, 613-620.

Sharma, B. R., Dhillon, S., \& Bano, S. (2009). Juvenile delinquency in India-A cause for concern. J Indian Acad Forensic Med, 31(1), 68-72.

Walker, J. T., \& Maddan, S. (2019). Statistics in criminology and criminal justice. Jones \& Bartlett Learning.

Young, S., Greer, B., \& Church, R. (2017). Juvenile delinquency, welfare, justice and therapeutic interventions: a global perspective. BJPsych bulletin, 41(1), 21-29. 